\title{
Villagers Participation in Rural Public Policy Making in China
}

\author{
Xingzhi $\mathrm{Wu}$ \\ Research Center of Scientific Outlook on Development and Zhejiang Development \\ Zhejiang Institute of Administration, Hangzhou 311121, China \\ E-mail: wuxingzhi@163.com
}

\begin{abstract}
Exploring in public policy making of villagers participation is the key point in the scientification and democratization of the policy. This paper takes the deliberative governance model in Zhejiang Province as example to study why and how villagers can participate in rural public policy making and how villagers' wills are taken into account in rural governance in China nowadays. And an effective policy making model of villagers participation in rural governance is set up and discussed at the end.
\end{abstract}

Keywords: Villagers participation, Rural public policy making, Democratic discussion, Deliberative governance model

\section{Introduction}

It is crucial for the scientification and democratization of rural public policy, which takes public interests as its goal, that there exists an efficient participation of villagers in the policy making process. Even more, the possibility of the delegitimation of state intervention in many spheres of public policy and the pursuing ultimate ends of survival and justice pose new possibilities for participation in advance societies all over the world. But in fact, as a result of the complexity of governance and the forceful power of the state, villagers always have no enough chance to take part in the policy making to express their reasonable appeals while the local government is beset with the hardness of getting the truth of the villagers' wills. This paper takes the deliberative governance model, which means the public policy is made only after the democratic deliberation between the villagers and local authority, in Wenling County, Zhejiang Province as example to study why and how villagers can participate in rural public policy making and how villagers' wills are taken into account in rural governance in China nowadays.

Before our analysis, two important assumption of the theory should be preinstalled. Firstly, public policy can not be independent of the existing political, economic and social environment and therefore the factors that influence the formulation of public policy is not only (in some time, not even mainly) the objectives of the policy itself. Secondly, in the public policy making process, the relevant participants are rational actors but only with limited ration. Due to the existence of the interests of social diversity, as well as cognitive and moral differences, the main different policy perspective on different issues of public policy may have different cognitive orientation, and may take different ways to influence the public policy process.

\section{The two cases of deliberative governance model in Zhejiang Province in South-east of China}

The democratic discussion in Wenling County, Zhejiang Province began in 1999 as an educational forum of rural agriculture modernization primarily which purpose is to adopt a kind of educational forms for the people to make face-to-face communication. After the promotion of the local government, the democratic discussion is widely practiced in the public policy process. Our analysis is based on two cases----Xinhe town's 2006 budget democratic discussion and Zeguo town's democratic discussion on urban construction.

On March 6-9th, 2006, in Xinhe Town, the budget democratic discussion was hold, in which 93 town NPCs and other 193 villagers attended to deliberate on the township-budget of the next year. The government has carried on many times the dialogue and discussion, puts forward 18 problems such as the administrative management, increase spending reduction education investment, etc. After the democratic discussion between government and the people, the presidium and budget review panel held a joint discussion meeting of National People's Congress, confirming the adjustment of 25 million yuan and 9 project total capital 237 million yuan which including the reduction of administrative fee. According to the report, and modify the government budgets in the second plenary meeting of the National People's Congress was approved by voting.

Zeguo Town's democratic discussion on urban construction project was held on March 20, 2006 in a middle school. This democratic discussion activities take "two rounds of grouping" discussion procedure, namely a meeting and group discussion, and the participators should finish two questionnaires before and after the discussion. The government, by surveying the questionnaire survey and statistics item, made an arrangement of all the project of urban construction from the most important to the most important sequence, and then, the government office conference was held, according to the survey results, to make construction project which would thereby be submitted to the local NPC for 
deliberation and voting.

The two cases this paper selects are the most successful and most typical democratic discussions in Wenling County during the last few years so this paper can provide an analysis with more feasibility and persuasiveness. The method of collecting the materials mainly has four kinds: democratic discussion convened by the villagers in the two questionnaires, villagers and government workers in the interview process for the record, structured democratic discussion observation and relevant literature and audio-visual materials from government departments. These different aspects of the material, basically show us where a villagers participation in public policy formulation of the model. Based on this, we will firstly analyze the practice process of these two cases, and the public interest and the expression of the integration theory explanation. Then, on local villagers participation in public policy formulation and policy, the quality of policy with villagers participation and the legitimacy of relationship problems are discussed. In the end, based on the analysis of the above, the author puts forward a villagers-participation-model in place of public policy, in order to seek effective decision-making model of villagers participation in our reality with local public decision-making model.

\section{The function and meaning of villagers participation in rural public policy making}

\subsection{Who are participating: the selection of civil representatives and the extensiveness}

Being in a society of diversification, different social groups or persons always appreciate different social goods which cannot be substituted each other. Also, one researcher has recently warned that NGOs focusing on social services are sometimes viewed as a potential counterweight to state power, so they are in fact "largely an extension of state power because they are heavily funded by the regimes as well, and their members - such as trade unionists and professionals rely on policies made at rulers' discretion."(Amy Hawthorne, 2005) As a result, direct and personal participation into the rural governance is especially essential for the villagers, and then, the selection of civil representative should be inclusive and extensive so as to everyone affected by the policy has a chance to voice their appeals. In the two cases discussed in this paper, random sampling and voluntary application are mainly introduced, of which the front one possesses more fairness and scientificalness at the expenses of the intense of deliberation, while the latter one expands the extensiveness of participation but also with some negative effect on the objectiveness of the policy.

The representatives in Zeguo Town's democratic discussion were selected by draw. According to population of each village, 2 percent of the population would be produced to be representatives, in total of 240 representatives, by random sampling that all villagers who are over 18 were recorded to reprogramming. From the results of sampling, the proportion of the representatives mainly account for its location in the total population, which means that this way of selection represents more accurately the the situation of local population distribution. In addition, 12 representatives were generated randomly from foreign employees in the large-scale enterprise, and five people supervisor were recommended by the National People's Congress presidium. And more, 32 young teachers in local middle schools, after related training, participated as directors and reporters in the democratic discussion groups.

By the way of the random sampling, all the delegates were strictly selected objectively and justly, but at the same time, it also may result in low levels of democratic discussion issues just as representatives of low visibility, lack of interests, etc. We shall come to this latter. Therefore, just as Chen Yimin, the chief of Theory Section of Propaganda Department of Municipal Party Committee, has said, if that the topic of democratic discussion is concerned with all the people, the way of random sampling would be just, but if only a few people were involved, such as a specific issues, the crowd was not suitable for sampling method. Participators in Xinhe Town's deliberative discussion were selected basically in two ways: voluntary application of the villagers and representatives from National People's Congress. Because of the professional government budget review, all the participators, including the National People's Congress and the representatives of villagers in democratic discussion, were got full training to ensure the quality of deliberation.

The voluntary application beside the NPC in Xinhe Town expanded largely the inclusiveness of decision-making process, while in Zeguo Town the deliberation by random sampling took the form to achieve the universality and representatives of fairness of principle. Here, there is a concern about the political participation of the floating population in rural public policy making. In some economically developed township, especially in the east coast of China nowadays, many of the floating population have been living there for a long time, basically in the local social life, and have a higher sense and belonging to the local economic and social development. But with regard to their political rights there, they are still marginal groups. In Zeguo Town's democratic discussion about 2006 town-construction project, it was obviously impartial that 237 representatives were selected from 120 thousand local permanent population while only 12 from 150 thousand floating population. Even in some other democratic discussion in many villages and towns, none of the floating population represented, and the huge contrast of the representative case of local population and floating population proportion in Zeguo Town is only an epitome of this phenomenon. Of course, the political participation of floating population problem is beyond the scope of this issue, not for further discussion.

\subsection{Villagers participation and the conformity of multi-interests}

The program of democratic discussion held by the protagonist is usually as follows: firstly, participants are informed of 
the democratic discussion content and some other information; and then, all participants take action of free group-dialogue, free discussion and random speech about the democratic discussion topics while all opinions are recorded. Also in Zeguo case, all participants were randomly assigned to 16 teams so that all villagers can transcend the social limits by open environment of mutual understanding and communication. In the morning group discussion, a foreign representative was warmly applauded for his insightful opinion about the way of urban greening financial arrangements. Some villagers have later said: "I've been feeling that the migrant workers would only pay attention to themselves, but actually they are also so enthusiastic about Zeguo Town development." Some others said "What they said is fairly reasonable." This kind of face-to-face contact and communication had obviously changed the villagers' prejudice against floating population.

Villagers participation in the two cases shows that the public deliberation is a process in which the multi-interests accommodate, adjust and compromise. After rational deliberative discussion, villagers, with their free and equal status, can reach the final toleration and understanding of each other, instead of escalation of the conflictions(Shengyong Chen, Xingzhi $\mathrm{Wu}, 2007)$. Of course, the deliberation is efficient only on the premise that people who are affected by the policy have enough representatives to participate the discussion otherwise their interest is likely to be deprived by majority.

Considering the possibility of interest dispute and possible existence of some important projects that government had not listed, Zeguo Town government fund 50 million in a 5-10\% of the reserve fund in the urban construction, with representatives of strong demand for construction project, prevent huge interest differences and upgrade of conflicts. In the construction of industrial capital investment and supporting for urban reconstruction funds, partial delegates to reach a consensus. Some villagers think need to increase the transformation and road with other villagers Zeguo Town industrial output in the financial revenue accounts based on high proportion of industry, supporting the importance of building. After several rounds of negotiations, most of the villagers paid more recognition and interests on road reconstruction investment.

In the case of Xinhe Town, representatives focused on the higher people's livelihood issues. With the appeals and importunities of most of the representatives, township government had had to reduce the amount of travel infrastructure spending from 200 million to 150 million, and raise the spending of drainage pipeline construction in residential area from 50 thousand yuan to 150 thousand yuan, while at the same time, 500 thousand yuan had been augmented to the renovation of old streets. With regard to budget of "500 thousand yuan of personnel training and visiting fee" project protested by almost all the village representatives for the government's neglect to training of National People's Congress and the villages, the government, after several exchanges of opinions and a hot debate, decided to revise this project and take up the training fee of National People's Congress and the villages.

Democracy is the various interest continuously game, adjustment, the process and mechanism of compromise. In this paper, the two cases of public consultation process is actually society benefit mutual adaptation and compromise in the process, on the basis of mutual respect, equality, freedom, and the rational consultation between villagers can effectively achieve mutual understanding and tolerant, rather than the conflict and upgrades. Of course, the effectiveness of the public consultation, when an important premise is the theme democratic discussion involves some specific interest groups, the group should have enough delegates, and otherwise it prone to most people deprived of minority interests. If the real stakeholder not only, or stakeholder participants, lack of third-party, objective neutral could lead to negotiate the bias results and injustice.

\subsection{The interaction of villagers participation with quality of policy making and the political legitimacy}

A perfect policy must be a combination of the quality of policy and a good consideration of villagers interests. That means the government should step back to make more participation of the citizens to improve the quality of policy while pushing forward the development of democratic process. Ironically, as Francis Fukuyama has recently reminded us, democracy is undermined when the state is too weak(Francis Fukuyama, 2004). When the government's capacity to enforce its will does not extend to substantial parts of a country, democracy is somehow undermined. Although villagers participation contributes to the quality of policy making at some extent by affording more information and intellectual insight, the case studied in this paper also shows that, the meaning of villagers participation in rural governance is somewhat closely related with political legitimacy. As a result, the ways and effects of this participation should be re-evaluated and reconstructed.

Any public decision-makings are a series of related policies and the essence of management, including technical constraints, rules, constraints, and budget constraints, etc, has some limits on the quality of villagers' participation. But on the other hand, in order to improve the quality of decisions, policy makers need more information about the real needs of the public. As the government is also limited rational actor in their knowledge, information and intelligent, and permitted by the various restrictions, villagers participation in public policy process, through various ways to deal directly with decision makers, will undoubtedly help decision-makers to obtain a more comprehensive search of the information resources in order to improve the quality of decisions. 
Urban construction fund, which is used to arrange the relationship between economic development and people's livings, is an important public policy. In order to understand the true opinion, Zeguo Town democratic discussion to choose, on behalf of the experts, representative of the democratic discussion content, speaker opportunities and policymakers to represent the five aspects of opinions about the system design, thus make public the representativeness, authenticity, make decision-making more accord with public opinion. And the survey results democratic discussion compared before and after two rounds of discussion, the second survey of the villagers' opinions. The disposal of concern, "Dan-ya Waste Transfer, Lan-tau Waste Transfer project in two questionnaires are listed first program" is a waste transfer station tree in the second questionnaire by $6^{\text {th }}$ rise to second place.

Extensive information source is the government, but the important guarantee of the breadth and depth of the villagers participation is often reverse effect, especially for some more formal, large and some special participation form. The urban construction democratic discussion democracy Zeguo Town negotiations issues, though the government budget, but part of the government's elaborate organization and better ensure the information sources of universality and democratic consultation, guarantee the quality of the authenticity of public opinion. Xinhe budget democratic discussion practice shows that, by the democratic congress before democratic discussion instead of the role of democratic discussion, now can use to activate the township's role, make it play their important matters of supervision and local authority. In the process of interest game is discussed in many consultations and communication, various other adjustment, and the profit on the basis of interest demand and villagers will transfer to decision-making system, helps to reduce the distortion of information policy, reduce and twisted by searching information of government policy, to help the government cost rationally set place quickly, public policy.

Public policy is committed to the realization of social public interests, or just for a few people, a group of special interests and service; this is the legitimacy of the government and its policy evaluation of basic standards(Tan Huo-sheng, 2007). Only let the public participation in government management and fully exert on the government's decision to ensure the effective, truly representative government. But in reality, the public debate on government policy effect is very limited; they lack of effective means for the government's behavior, especially effective in the National People's Congress system remains to be perfect. So, why should the government in public places in the policy in the democratic discussion this policy tool? Studies have shown that the government in the decision-making process of the choice of policy tools, policy tool attribute often is the main factor. Wesley M. Cohen and in Daniel A. Levintha have had good attribute generalization: (1) Resources, including concentration of administrative cost and operation simple; (2) Goals, including accuracy and selective; (3) Political risk, including support and opposition, public awareness and the probability of failure; (4) Of the constraints, including national behavior of the difficulties and force to restrict government behavior principle of ideology(Michael Howlett, M Ramesh, 1995).

Traditional Chinese government decision-making model can be favored by first-line managers, partly because the traditional arrangement system is a simple and safe rule for it costs less and has been a more convenient policy tool for grassroots governments to reduce their political risks. In the current social transition period, and the differentiation in social subject of interest differentiation between the polls also obvious, there is an obvious diversification, the government in the process of formulating public policies will inevitably produce deviation between the public. But this deviation caused by villagers often struggle with even. In recent years, in Zhejiang, enjoys and the farmers and Chang-xing struggle can be regarded as the events from the typical example. democratic discussion for government decision making and it provides a new way to satisfy basically in the current social transformation of government under the background of the requirement of policy tool to attribute the feasibility and operating on the goal of innovation and control, and the political benefit of government itself is the essence of smaller binding, etc. In the middle of cases, we can find that, let the villagers participation in the decision-making process is an important goal is to widely to express, on the basis of the high degree of villagers to accept the policy. Especially when the decision of executive process needs villagers of understanding and cooperation, absorb villagers participation in order to improve the decision-making of decision-making acceptable degrees appear particularly important.

\section{Effective policy making model of villagers participation in rural governance in China}

By probing into the deliberative governance model in Zhejiang Province, an effective policy making model of villagers participation in rural governance can be proposed and discussed. Based on the case of Zhejiang possessing democratic discussion, we believe, in the contemporary Chinese villages in the context of the development of democratic politics, the villagers participation in rural public policy making has revealed us a way of thinking of, also a framework for analysis, how to realize the villagers participation in government decision making and make a balance between the villagers interests and the quality of public policy.

First, due to the lack of effective monitoring and restriction mechanism on the public administration, villagers participation in the rural policy making implies, in fact, an administration of process-regulation, in which the improvement of the quality, at some extent, has been the byproduct of villagers' deliberation in their participation. At that, restricting the centralized power and expressing their requirement have mainly rooted in the villagers participation. 
In the policy of quality requirements and villagers participation in relation to the government, due to the lack of effective supervision and restriction mechanism, the villagers to participate in more rural public policy to reflect a kind of "process for the administrative pattern in regulation", the higher the quality of decisions, to some extent, become villagers to participate in discussions of the rational byproduct. Therefore, the local government policy on quality requirements often not decide whether the villagers participation in the key factors. Restrict the government too centralized power and realize the interests of villagers of expression, is a villagers participation in government decision making process requirements, and most major civic participation depends on the final realization of the requirements of the response.

Secondly, as the rural public policy is often an integrated embodiment of multiple targets, the acceptability of the policy, with regard to more and more social confliction and intense appeals, makes a priority over the quality of the policy. This has largely affected the function of villagers participation. In rural areas of public policy is often the integrated embodiment of multiple targets, the most important is, it in the current political system for realizing the legitimacy of the government in the task to a certain extent, plays an "administrative absorption of politics"(Yeo-Chi King, 1997). In the case of democracy, democratic discussion contradiction with NPC session, promoted the political effect; assembly while in middle cases of public opinion survey for the final decision is more focused on the acceptability of the policy and government behavior. So, contrary to Thomas model is, in our local public policy formulation, considering villagers is more and more intense interest conflicts and acceptable degrees of policy focus more than likely to the quality policy.

Thirdly, the policy making model of villagers participation in rural governance in largely still has been enslaved to the already authority structure of government, and its validity remains greater uncertainty. This calls for further system reform and institution innovation to improve villagers participation and public reason in the decision-making process. Possessing democratic discussion is mainly in the field of state administrative villages by redesign of corporate governance structure, and can produce to make positive changes in the institutional environment, thus expanded response to the village management, public participation in the field of civil rights, expand space, is a public power continuously to return the society. Therefore, our country rural area public policy formulation process is a kind of villagers participates in activities of face, not simply for government decision making process to obtain information on the policy, strengthen the understanding or establish cooperative relations.

Some other innovative ways of policy making, which share some common merits with the Zhejiang cases, have been investigated and practiced in many countries, such as "collaborative policy making" which was proposed by Center for Collaborative Policy Research in California University, focusing on the deliberative process of policy making between different sectors and the collaboration of multi-interests (Clare M Ryan, 2001). All of those innovations show that it is not only possible but also imperative to take an effective policy making model of villagers participation in rural governance.

\section{Conclusions}

This paper defends the possibility of villagers participatory in rural areas by presenting a revised process analysis of participatory to explain the theory of participatory democracy which was developed in the work of Rousseau, J.S. Mill, and some other classical theorists, and proposes that participation produces popular control of the issue-agenda, decision-making, and implementation (Joel D. Wlofe, 1985). It does work nowadays in most countries of the world, as Carole Pateman asserts, "participation develops and fosters the very qualities necessary for it; the more individuals participate the better able they become to do so"(Carole Pateman, 1970).Our research has shown that villagers participation is possible and necessary in rural public policy making in China nowadays, and the good governance in rural results from villagers offering their support to leaders in return for leaders' advocacy of villagers' self-defined interests.

Villagers participation, usually meant programs only contrived by government to provide opportunities for those masterful citizens, in Zhejiang rural public policy making has manifested that there is more initiative of innovation from the grassroots and more attention should be paid to collaboration and deliberation. Although the relationship between villagers participation and the good governance of the countryside in China has not been clear thorough, at the very least, the good governance is one instance of much larger process of villagers participation, and villagers participation unquestionably involves both the development of civic identity and participation in good governance.In summary, by offering an explanation of these processes of villagers participation in Zhejiang rural areas, this revised model of villagers participation will hopefully contribute to a greater realization of the ideals of harmonious society and new development of the rural areas.

\section{References}

Amy Hawthorne. (2005). Is Civil Society the Answer? in Thomas Carothers and Marina Ottaway, eds., Uncharted Journey: Promoting Democracy in the Middle East. Washington,D.C: Carnegie Endowment for International Peace, Brookings Institution Press. 
Carole Pateman. (1970). Participation and Democratic Theory. Cambridge University Press.

Clare M Ryan. (2001). Leadership in Collaborative Policy Making: An Analysis of Agency Roles in Regulatory Negotiations. Policy Science. No.34.

Francis Fukuyama. (2004). State-Building: Governance and World Order in the 21st Century. Ithaca: Cornell University Press.

Joel D. Wlofe. (1985). A Defense of Participatory Democracy. The Review of Politics. Vol. 47, No.3.

Michael Howlett, M Ramesh. (1995): Study Public Policy: Policy Cycles and Subsystems. Oxford: Oxford University Press.

Shengyong Chen \& Xingzhi Wu. (2007). Citizens Participation and Local Public Policy Making. The Academics. No.5. Tan Huo-sheng. (2007). Democratic Deliberation and Political Legitimacy. Beijing: The Law Press.

Yeo-Chi King. Ambrose. (1997). Administrative Absorption of Politics: the Political System of Hong Kong. Chinese Politics and Culture. Oxford: Oxford University Press. 